\title{
Common Infectious Agent in Urogenital Tract among Ladies at Omdurman Locality in Omdurman Maternity Hospital \& Elsuadi Hospital in Sudan
}

\author{
Kunna A ${ }^{1}$, Sumeya A.Kheiri ${ }^{1}$, Khairy S Ismail ${ }^{2}$, Hassan A Elkheir ${ }^{3}$, Samah Fadol ${ }^{4}$, \\ Suaad Elnour ${ }^{2}$, and Umbeli Taha ${ }^{2}$ \\ ${ }^{1}$ Department of Obstetrics and gynecology, University of Bahri, Sudan. \\ ${ }^{2}$ Department of Obstetrics and gynecology, Omdorman Islamic university, Sudan. \\ ${ }^{3}$ Omdorman Maternity Hospital, Central laboratories, Sudan. \\ ${ }^{4}$ Consultant obstetrician at Omdorman Maternity Hospital, $\mathrm{KMOH}$. \\ *Corresponding Author: Dr. Akram Elkhier Hassan, Omdorman Maternity Hospital, Central \\ laboratories. Khartoum, Sudan
}

\begin{abstract}
This was descriptive cross-sectional hospital-based study, The study was carried out in the period from March 2016 to August 2016. The study was conducted at Omdurman locality hospitals, Omdurman maternity hospital, New Saudi Hospital. Study population was all women attend the study area during the study period complained of vaginal discharge, pelvic pain, dysparnuia and genitourinary symptoms. : total of about 202 patients were included in this study. Type of the sample is stratified random one. Participants was seen personally in different obstetrics and gynecological clinics in Omdurman locality hospitals. A full details history was taken by the authors. List of investigations was done including according to her complain. High vaginal swap was taken for each participant for culture and Urine for culture and sensitivity. The women in the study according to gestational age less than 24 weeks were 15 (7.4\%), 2529 weeks were 17 (8.4 s\%), 30-34 weeks were 53 (26.2\%), 35-39 weeks were eleven (5.4\%) ,40 weeks and more were seven (3.5\%) and none pregnant were 99(49\%). The women in the study according to type of infection STD were 90 (44.6\%) kidney infection 10 (5\%), uncomplicated UTI $15 \%$. The whole data are analyzed by using the computerized program, (SPSS), then results were presented as tables and figures. Eventually, the study came to a conclusion that the most incidence of vaginal infection in this study is candidiasis $27.3 \%$ followed by Stapha aureus 16.9\%, proteus 9.9\% and Ecoli 7.9\%, Ecoli is the most incidence urinary tract infection $21.8 \%$ followed by Stapha aureus $14.4 \%$, streptococcus $9.4 \%$ and proteus $8.9 \%$ with applying international standard clinical criteria supports the diagnosis our microbial isolates showed typical biological features, however, the clinical features did not always concur.
\end{abstract}

Keywords: Maternity, Urinary Tract Infection (UTI), Vaginitis, World Health Organization (WHO), Sudan.

\section{INTRODUCTION}

Urinary tract infections are viewed as the most well-known bacterial disease as indicated by the National Ambulatory Medical Care Survey accounted for nearly 7 million emergency department visits, resulting in 100,000 hospitalization in US. ${ }^{[1]}$

In society urogenital infections and sexually transmitted diseases are continuously increasing but timely diagnosis lead to treatment of majority of them. Urogenital contaminations are one of the most widely recognized reasons for introduction to gynecologist appropriate determination and well-chosen treatment and the genital minimal hygiene measures may provide long term beneficial effects especially in young segment of the female, which is also the most affected by this pathology. ${ }^{[2]}$
Every year, it is assessed that 1 billion ladies around the globe experience the ill effects of sexually transmitted urogenital infections albeit most patients react to antimicrobial treatment, the repeat rate is high band related to symptoms and confusions, for example, PID, infertility, PROM, preterm labor. ${ }^{[3}$

Bacterial Vaginitis: Fundamental Vaginosis is considered as an excess of anaerobic creatures joined with the loss of defensive lactobacilli typically found in the sound vagina. This disease normally found in ladies matured 17 30 years [4], but on the other hand, it is common in more seasoned ladies and it might happen without symptomatology, however, it is by and large connected with a homogenous white vaginal release. 
Yeast Vaginitis: It is an exceptionally basic issue, evaluated to influence around 1:5 dark American ladies and near 1:10 white ladies during some random two-month time period. ${ }^{[5]}$

Despite the fact that there are challenges in finding and compelling treatment regimens (fundamentally because of high repeat rate), etiology have been all around contemplated as with UTI, and bacterial Vaginosis, the digestive tract is the principle wellspring of the tainting contagious life form and abundance in the vagina can pursue disturbance of the typical greenery following utilization of range antitoxin treatment. It is normally portrayed by white vaginal release, foulness, nonhomogeneous vaporous appearance joined by vaginal tingle and bothering, and proof of vaginal irritation. White Candida Albicans is the significant reason for diseases (85\%)[5], other yeast, for example, candida Glabrata, candida Tropicalis, Candida Krusei.

Urinary Tract Infection: Lower UTI in ladies is viewed by certain doctors as a minor bother to their patients, yet this malady is liable for noteworthy symptomatology, horribleness, and loss of nature of life $\{6\}$. It expenses to medicinal services suppliers adding up to over $\$ 6$ billion every year overall [7]. It is additionally an issue in pregnancies influencing around $5 \%$ of ladies and of that $20 \%$ may secure pyelonephritis. Traditionally 105 life forms for each $\mathrm{ml}$ of pee or more have been viewed as a satisfactory bacterial tally. Notwithstanding, in ladies, consider of low as 103 creatures for every $\mathrm{ml}$, especially whenever related with irritative bladder manifestations and nearness of expanded WBCs in the pee are presently viewed as demonstrative of genuine UTI. The typical side effects of dysuria, recurrence of pee, and periodic haematuria, are not constantly present, and bacteriuria of 105 May happen in patients who are absolutely (asymptomatic bacteriuria) will in general increment with age, and it might happen in up to $10 \%-15 \%$ of postmenopausal ladies. E. coli is a causative specialist in most ladies experiencing UTI $(85 \%)$. [7] The UTI repeat rate, near half sometimes, represents an a lot more prominent treatment challenge. These sickness elements furnish the clinician with both an indicative and treatment challenge. The way that exact determination relies upon both the nearness of indications and positive pee culture and vaginal swap culture, in spite of the fact that in most outpatient setting this analysis made without the advantage of culture.
Investigations: All ladies with repetitive UTI ought to experience a physical assessment to assess urogenital life systems and estrogenization of vaginal tissues and to distinguish prolapse. Post-void lingering pee volume ought to be estimated. Diabetes screening is demonstrated in patients with different riskfactors, for example, family ancestry and stoutness. Most ladies don't require broad urologic examinations. ${ }^{[8]}$ In any case, ladies who endure contamination with living beings that are not regular reasons for UTI, for example, Proteus, Pseudomonas, Enterobacter, and Klebsiella may have basic variations from the norm or renal calculi. They would profit by imaging investigations of the upper urinary tract and cystoscopy. ${ }^{[9]}$ Ladies who have industrious hematuria after goals of their contamination additionally require a total urologic workup. [10] Albeit empiric treatment dependent on manifestations is commonly exact and financially savvy, ladies who are felt to be in the beginning periods of an issue with intermittent UTI ought to have reported societies. ${ }^{[11]}$ Pee culture not just fills in as the best quality level for analytic exactness yet in addition gives explicit data about the uropathogenic and its anti-infection susceptibilities. ${ }^{[11]}$ The standard meaning of an UTI on culture is > 100000 state framing units for every HPF. This worth has magnificent particularity however an affectability of just $50 \% .^{[11]}$ In ladies with manifestations of an UTI > 1000 settlement framing units for each HPF is viewed as adequate to record contamination without bargaining explicitness. The affectability to identify contamination is $80 \%$ and the explicitness $90 \%$. At the point when a "perfect catch" or midstream system is utilized to get a pee test, the paces of tainting with vaginal vegetation are roughly 30\%.24 The nearness of $>20$ epithelial cells for every HPF on urinalysis recommends sullying by vaginal discharges. [10] In light of the fact that microscopic organisms lessen urinary nitrates to nitrites, the utilization of pee dipstick investigation can be useful. A positive outcome for the most part shows disease, with an explicitness of $92 \%$ to $100 \%$ and an affectability of $19 \%$ to $48 \% .25$ A negative outcome doesn't preclude contamination if the patient is symptomatic. A few microscopic organisms, for example, Staphylococcus saprophyticus come up short on the chemicals to decrease nitrates. On the off chance that the pee has not been available in the bladder for at any rate 4 hours, there might not possess been adequate energy for the response to happen. ${ }^{[12]}$ 
Leukocyte esterase is delivered by neutrophils and shows pyuria, which is related with UTI. Living beings other than uropathogens can deliver leukocyte esterase. Hence, this is a touchy ( $72 \%$ to $97 \%$ ) yet not explicit ( $41 \%$ to $86 \%$ ) test for UTI in ladies. Blood on dipstick can affirm contamination, yet this can be related with other clinical conditions and along these lines is progressively delicate (68\% to $92 \%$ ) than explicit (42\% to $46 \%$ ) for UTI. ${ }^{[12]}$

Pregnancy of genitourinary tract infection All ladies with repetitive UTI ought to experience a physical assessment to assess urogenital life structures and hete-rogenization of vaginal tissues and to distinguish prolapse. Post-void remaining pee volume ought to be estimated. Diabetes screening is demonstrated in patients with other hazard factors, for example, family ancestry and weight. Most ladies don't require broad urologic examinations. ${ }^{[8]}$ In any case, ladies who endure disease with life forms that are not regular reasons for UTI, for example, Proteus, Pseudomonas, Enterobacter, and Klebsiella may have auxiliary variations from the norm or renal calculi. They would profit by: For pregnant ladies with symptomatic or asymptomatic bacteriuria, the danger of preterm conveyance and low birth weight baby is essentially expanded. ${ }^{[13]}$ Hooton and Stamm suggest a subsequent culture for trial of fix seven days after fruition of treatment and month to month follow-up until the consummation of the pregnancy Signs for prophylaxis are on the whole ladies with a pre-pregnancy history of repetitive UTIs, tenacious symptomatic or asymptomatic bacteriuria after two anti-toxin medications, and after only one UTI for a lady who has different conditions that conceivably increment the danger of urinary complexities during the scene of UTI (e.g., diabetes or sickle cell quality). Both persistent and post-coital prophylaxis regimens have been demonstrated to be viable, and specialists of decision are nitrofurantoin $(50 \mathrm{mg})$ and cephalexin $(250 \mathrm{mg}){ }^{[14-15]}$ methods, Doctors must, hence, bend over backward to hold these abilities, to alter and improve them every way under the sun, and pass them on.

Imaging investigations of the upper urinary tract and cystoscopy. ${ }^{[9]}$ Ladies who have persevering hematuria after the goals of their disease likewise require a total urologic workup. ${ }^{[10]}$ Albeit empiric treatment dependent on side effects is commonly exact and financially savvy, ladies who are felt to be in the beginning periods of an issue with intermittent UTI ought to have reported societies. [11] Pee culture not just fills in as the highest quality level for symptomatic exactness yet in addition gives explicit data about the uropathogenic and its anti-toxin susceptibilities. ${ }^{[11]}$ The standard meaning of an UTI on culture is > 100000 settlement framing units for each HPF. This worth has astounding explicitness yet an affectability of just $50 \%$. ${ }^{[11]}$ In ladies with side effects of an UTI > 1000 state framing units for every HPF is viewed as adequate to archive contamination without trading off particularity. The affectability to identify contamination is $80 \%$ and the explicitness $90 \%$. At the point when a "spotless catch" or midstream strategy is utilized to get a pee test, the paces of defilement with vaginal vegetation are around $30 \% .24$ The nearness of $>20$ epithelial cells for every HPF on urinalysis recommends sullying by vaginal discharges. ${ }^{[10]}$ In light of the fact that microscopic organisms decrease urinary nitrates to nitrites, the utilization of pee dipstick examination can be useful. A positive outcome normally shows contamination, with a particularity of $92 \%$ to $100 \%$ and an affectability of $19 \%$ to $48 \% .25$ A negative outcome doesn't preclude disease if the patient is symptomatic. A few microorganisms, for example, Staphylococcus saprophyticus come up short on the chemicals to decrease nitrates. In the event that the pee has not been available in the bladder for in any event 4 hours, there might not possess been adequate energy for the response to happen. ${ }^{[12]}$ Leukocyte esterase is delivered by neutrophils and demonstrates pyuria, which is related with UTI. Life forms other than uropathogens can deliver leukocyte esterase. Subsequently, this is a touchy ( $72 \%$ to $97 \%$ ) yet not explicit (41\% to $86 \%$ ) test for UTI in ladies. Blood on dipstick can affirm disease, however this can be related with other clinical conditions and in this manner is increasingly touchy (68\% to $92 \%$ ) than explicit (42\% to $46 \%$ ) for UTI. ${ }^{[12]}$

\section{Justification}

- Urogenital contaminations not brought about by sexual transmission, in particular, yeast vaginitis, bacterial Vaginosis, and urinary tract disease stay a significant therapeutic issue as far as the number of ladies influenced every year. Although antimicrobial therapy is generally affective at eradicating these infections, there is still high incidence of recurrence.

- The patient's personal satisfaction is influenced and numerous ladies become 
Common Infectious Agent in Urogenital Tract among Ladies at Omdurman Locality in Omdurman Maternity Hospital \& Elsuadi Hospital in Sudan

baffled as it additionally conveys a high danger of long haul difficulties.

- Need to review the causative operator, accelerating elements and difficulties of urogenital tract diseases among Sudanese ladies.

\section{OBJECTIVES}

\section{General Objective}

To determine the most common causes of urogenital tract infections among Sudanese women.

\section{Specific Objectives}

- To survey the hazard factors for urogenital tract diseases.

- To determine the most common age group that affected with urogenital tract infections.

- To determine the drug and the response.

\section{Methodology}

\section{Study Design}

This was descriptive cross-sectional hospitalbased study.

\section{Study Duration}

The study was done in the period from Walk 2016 to August 2016.

\section{Study Area}

The study was conducted at Omdurman locality hospitals, Omdurman maternity hospital, New Saudi Hospital.

\section{Study Population}

Study population was all women attend the study area during the study period complained of vaginal discharge, pelvic pain, dysparnuia and genitourinary symptoms.

\section{Inclusion Criteria}

All women who agreed to participate in the study.

\section{Exclusion Criteria}

Study was exclude all women taken antibiotic within days at time of study, ladies with genital danger and the individuals who douched their vagina with compound and patients would avoid the examination.

\section{Sample Size}

The sample size was determent according to the formula:

$$
\mathrm{n}=\frac{\mathrm{t}^{2} \times \mathrm{p}(1-\mathrm{p})}{\mathrm{m}^{2}}
$$

\section{Description}

$\mathrm{n}=\quad$ required sample size

$\mathrm{p}=\quad$ assumed incidence $(16 \%)$

$\mathrm{t}=\quad$ confidence level at $(95 \%)$

(Standard value of 1.96)

$\mathrm{m}=$ margin of error at $(5 \%)$

(Standard value of .05)

$1.96 \times 1.96 \times .16(1-.16)$

$.05 \times .05$

$3.842 \times .1344=202$

.0025

Sample Size: total of about 202 patients were included in this study.

Type of the sample is stratified random one.

\section{Sampling Technique}

Participants was seen personally in different obstetrics and gynecological clinics in Omdurman locality hospitals.

A full details history was taken by the authors.

List of investigations was done including according to her complain:

1- High vaginal swap was taken for each participant for culture

2- Urine for culture and sensitivity.

\section{Data Collection Tools}

1- This was done through a questionnaire, checked by the authors at the end of each day and subsequently coded to ease analysis, and then coded data was entered into the prepared data sheets into the computer. Continuous variables e.g. Age was recoded into categorical variables to aid statistical analysis.

2- High vaginal swap wastaken for each participant for culture under specialist supervision.

Mid-stream pee tests were gathered utilizing sterile compartment around the same time of enrolment. Every one of the examples were investigated inside an hour of assortment utilizing dipstick (Mannheim $\mathrm{GmbH}$, Germany) adhering to the producer's guidelines, at that point tests were broke down for culture and affectability. Utilizing standard quantitative circle a $1 \mu \mathrm{l}$ and $10 \mu \mathrm{l}$ were utilized to vaccinate 
pee tests on Cysteine lactose electrolyte lacking Agar, MacConkey and Blood agar plates (OXOID-Britain). Plates were brooded for $24 \mathrm{hr}$ at $37^{\circ} \mathrm{C}$. A determination of UTI was made when there were at any rate 105 settlement framing unit $(\mathrm{CFU}) / \mathrm{ml}$ of pee. S. aureus was recognized by pioneer morphology, grampositive recoloring, positive catalase action, and positive coagulation of citrated bunny plasma (bioMerieux, Marcyl'Etoile, France). The plate dispersion technique was utilized to decide powerlessness of the disengages as recently portrayed. Singular provinces were suspended in ordinary saline to $0.5 \mathrm{McFarland}$ and utilizing sterile swabs the suspensions were immunized on Muller Hinton agar for 18-24 hr. E. coli ATCC 25922 was utilized as control strains. For gram-negative and positive microbes the accompanying circles were tried: Amikacine, Cefixime, Cefruxime, ceftriaxone, Cephalic, cefodox, Clindamycin, Doxycycline, Erythromycin, Metronidazole, Gentamycine, Vancomycin, Meronym. amoxicillin $(25 \mu \mathrm{g})$, co-trimoxazole (SXT) $(1.25 / 23.75 \mu \mathrm{g})$, nitrofurantoin $(300 \mu \mathrm{g})$, ciprofloxacin $(5 \mu \mathrm{g})$, nalidixic corrosive $(30 \mu \mathrm{g})$, amoxicillinclavulanic corrosive $(20 \mu \mathrm{g} / 10 \quad \mu \mathrm{g})$, and norfloxacin $(5 \mu \mathrm{g})$, Symptomatic patients were given amoxicillin/ clavulanate as exact treatment before culture results. All patients were approached to return for results following 2 days. At that point patients care at Antenatal Consideration Center has been proceeded by her overseeing obstetrician in the specific unit. Data Analysis: The gathered information were investigated by PC utilizing Measurable Bundle for Sociologies (SPSS) adaptation 22, Excell 2007 for figures. The mean, standard deviation was utilized for information factors, P-esteem trial of hugeness was utilized, $\mathrm{x} 2$ test and crossclassification will utilized in the investigation.

\section{Ethical Consideration}

- Ethical clearance from the ethical committee of the Sudan Medical Specialization Board, Council of Obstetrics and Gynecology was obtained.

- Official agreement from the general managers of different gynecological clinics in Omdurman locality hospitals was preceded the conduction of the study.

Verbal consent, which stated the purpose of the study, was taken from all participants in the study.

\section{RESULT}

During the examination time frame aggregate of 202 ladies were remembered for the investigation after they satisfied the criteria of consideration, their statistic information were contemplated, their obstetrical exhibition and gynecological history were taken, with midstream pee and high vaginal swab were attempted and their dispersed in table and figures is appeared as pursue:

Table1. Distribution of Patients according to Gestational age $(N=202)$

\begin{tabular}{|c|c|c|}
\hline Gestational age & Frequency & Percent\% \\
\hline$<24$ & 15 & 7.4 \\
\hline $25-29$ & 17 & 8.4 \\
\hline $30-34$ & 53 & 26.2 \\
\hline $35-39$ & 11 & 5.4 \\
\hline 40 and more & 7 & 3.5 \\
\hline Not pregnant & 99 & 49.0 \\
\hline Total & 202 & 100.0 \\
\hline
\end{tabular}

Table2. Distribution of Patients according to discharge with Itching $\quad(N=202)$

\begin{tabular}{|c|c|c|}
\hline Discharge with Itching & Frequency & Percent $\%$ \\
\hline discharge with Itching & 115 & 56.9 \\
\hline discharge with- out Itching & 24 & 11.9 \\
\hline No discharge & 63 & 31.2 \\
\hline Total & 202 & 100.0 \\
\hline
\end{tabular}

Table3. Distribution of Patients according to Discharge with Bad odor $(N=202)$

\begin{tabular}{|c|c|c|}
\hline Discharge with bad odor & Frequency & Percent $\%$ \\
\hline Discharge with bad odor & 85 & 42.1 \\
\hline Discharge with bad odor & 54 & 26.7 \\
\hline No discharge & 63 & 31.2 \\
\hline Total & 202 & 100.0 \\
\hline
\end{tabular}


Common Infectious Agent in Urogenital Tract among Ladies at Omdurman Locality in Omdurman Maternity Hospital \& Elsuadi Hospital in Sudan

Table4. Distribution of Patients according Type of Infection (N=202)

\begin{tabular}{|c|c|c|}
\hline Type of Infection & Frequency & Percent $\%$ \\
\hline STI & 90 & 44.6 \\
\hline Kidney infection & 10 & 5.0 \\
\hline uncomplicated UTI & 31 & 15.3 \\
\hline no history of infection & 71 & 35.1 \\
\hline Total & 202 & 100.0 \\
\hline
\end{tabular}

Table5. Distribution of Patients according to History of steroids $(N=202)$

\begin{tabular}{|c|c|c|}
\hline History of steroids & Frequency & Percent\% \\
\hline Steroid user & 12 & 5.9 \\
\hline Not steroid user & 190 & 94.1 \\
\hline Total & 202 & 100.0 \\
\hline
\end{tabular}

Table6. Distribution of Patients according to History of Diabetes $(N=202)$

\begin{tabular}{|c|c|c|}
\hline History of Diabetes & Frequency & Percent\% \\
\hline Had diabetes & 21 & 10.4 \\
\hline Not Diabetes & 181 & 89.6 \\
\hline Total & 202 & 100.0 \\
\hline
\end{tabular}

Table7. Distribution of Patients according local examination finding $(N=202)$

\begin{tabular}{|c|c|c|}
\hline Local examination finding & Frequency & Percent $\%$ \\
\hline Vaginal discharge & 138 & 68.3 \\
\hline local inflammation & 23 & 11.4 \\
\hline No discharge no inflammation & 41 & 20.3 \\
\hline Total & 202 & 100.0 \\
\hline
\end{tabular}

Table8. Distribution of Patients according High Vaginal Swab Growth Result (N=202)

\begin{tabular}{|c|c|c|}
\hline Result & Frequency & Percent\% \\
\hline Growth & 179 & 88,6 \\
\hline No growth & 23 & 11.4 \\
\hline Total & 202 & 100.0 \\
\hline
\end{tabular}

Table9. Distribution of Patients according to Number of Microorganism in high vaginal swab $(N=202)$

\begin{tabular}{|c|c|c|}
\hline Number of microorganism & Frequency & Percent\% \\
\hline One & 163 & 80.7 \\
\hline Two & 14 & 6.9 \\
\hline three & 2 & 1 \\
\hline No growth & 23 & 11.4 \\
\hline Total & 202 & 100.0 \\
\hline
\end{tabular}

Table10. Distribution of Patients according to Number of microorganism in Urine culture $(N=202)$

\begin{tabular}{|c|c|c|}
\hline Number of Microorganism & Frequency & Percent\% \\
\hline One & 163 & 99.5 \\
\hline Two & 14 & .5 \\
\hline No growth & & 100.0 \\
\hline Total & 202 & \\
\hline
\end{tabular}

Table11. Distribution of Patients according to Type of microorganism in high vaginal Swab $(N=202)$

\begin{tabular}{|c|c|c|}
\hline Type of microorganism & Frequency & Percent\% \\
\hline Ecoli & 16 & 7.9 \\
\hline pseudomonas & 5 & 2.4 \\
\hline Kellibesila & 12 & 5.9 \\
\hline Staphaaureus & 34 & 16.9 \\
\hline Proteus & 20 & 9.9 \\
\hline Streptococus & 7 & 3.5 \\
\hline Candida & 55 & 27.3 \\
\hline Bacterial vaginosis & 4 & 2 \\
\hline Trichomonas & 9 & 4.5 \\
\hline Normal flora & 8 & 3.9 \\
\hline Coliform & 9 & 4.4 \\
\hline No microorganism & 23 & 11.4 \\
\hline Total & 202 & 100 \\
\hline
\end{tabular}


Common Infectious Agent in Urogenital Tract among Ladies at Omdurman Locality in Omdurman Maternity Hospital \& Elsuadi Hospital in Sudan

Table12. Distribution of Patients according to Number of Microorganism in Urine Culture (N=202)

\begin{tabular}{|c|c|c|}
\hline Type of microorganism & Frequency & Percent $\%$ \\
\hline Ecoli & 44 & 21.8 \\
\hline Pseudomonas & 4 & 8.4 \\
\hline Kellibesila & 17 & 14.4 \\
\hline Staphaaureus & 29 & 8,9 \\
\hline Proteus & 18 & 9.4 \\
\hline Streptococcus & 19 & 1 \\
\hline Trichomonas & 2 & 0.9 \\
\hline Enterococcus & 2 & 1.5 \\
\hline Candida albicans & 3 & 31.7 \\
\hline No microorganism & 64 & 100 \\
\hline Total & 202 & \\
\hline
\end{tabular}

Table13. Distribution of Microorganism according to Drug Sensitivity and Resistance (N=202)

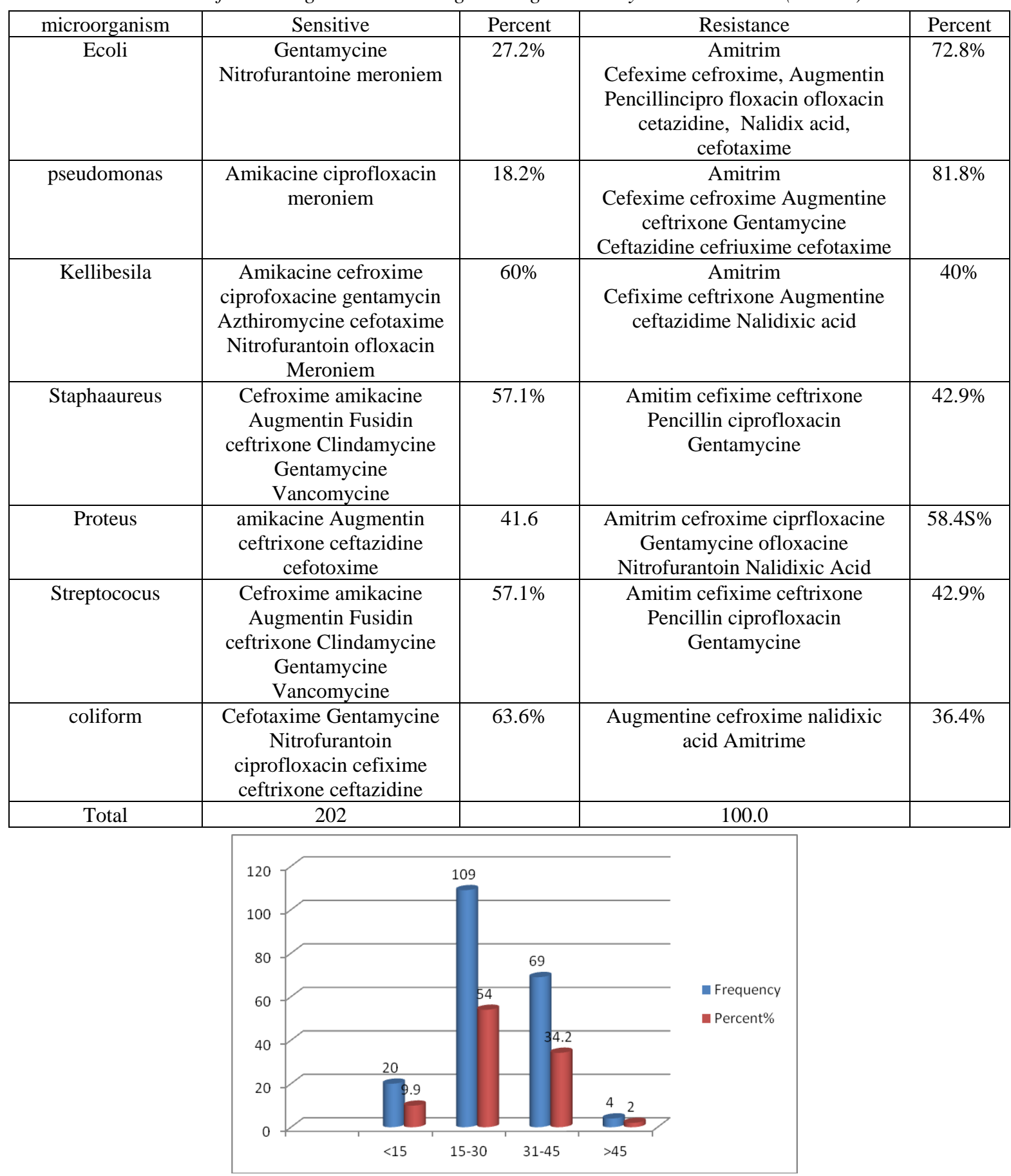

Figure1. Distribution of Patients according to Age (N=202) 
Common Infectious Agent in Urogenital Tract among Ladies at Omdurman Locality in Omdurman Maternity Hospital \& Elsuadi Hospital in Sudan

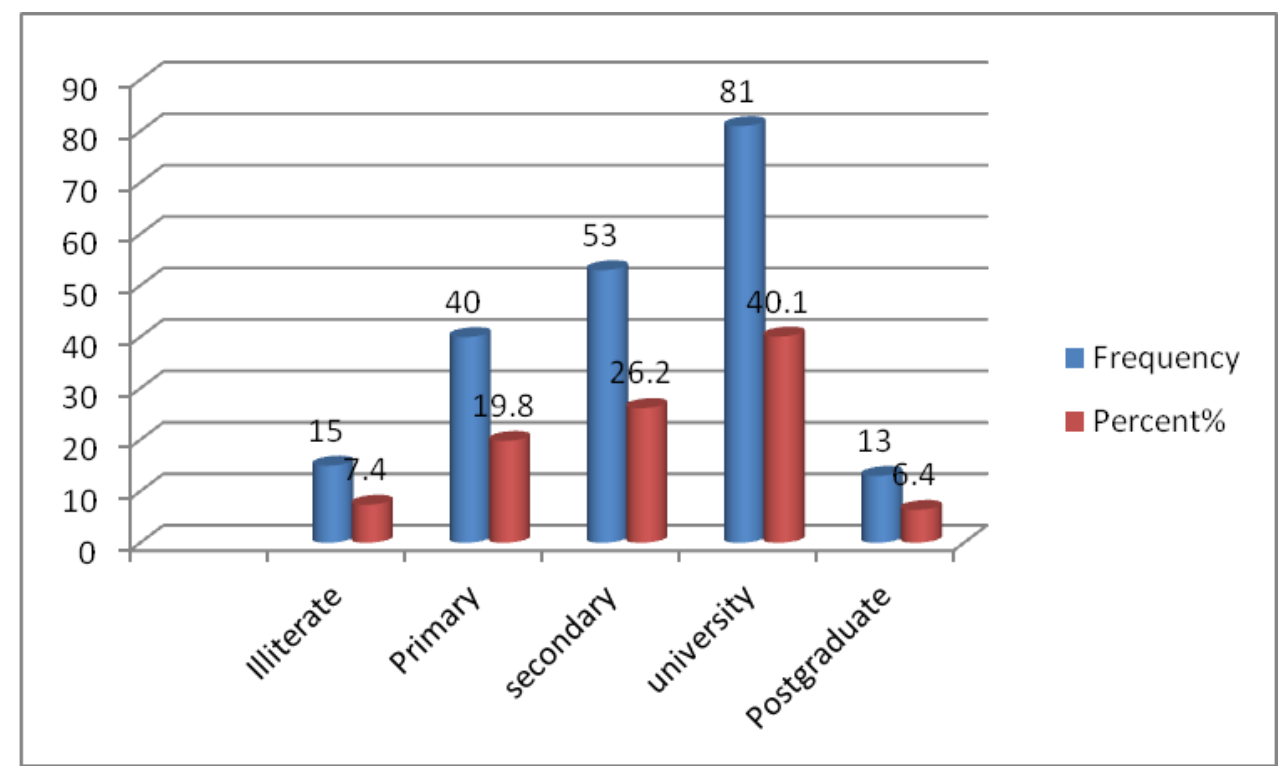

Figure2. Distribution of Patients according to Educational level (N=202)

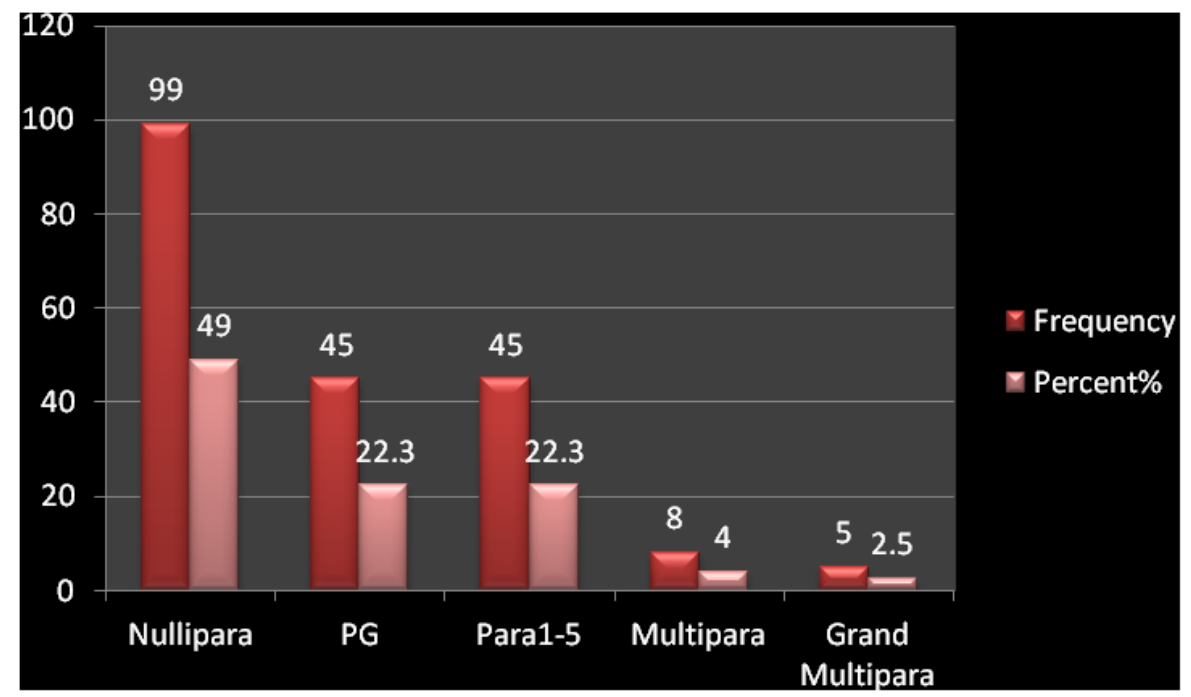

Figure3. Distribution of Patients according to Parity (N=202)

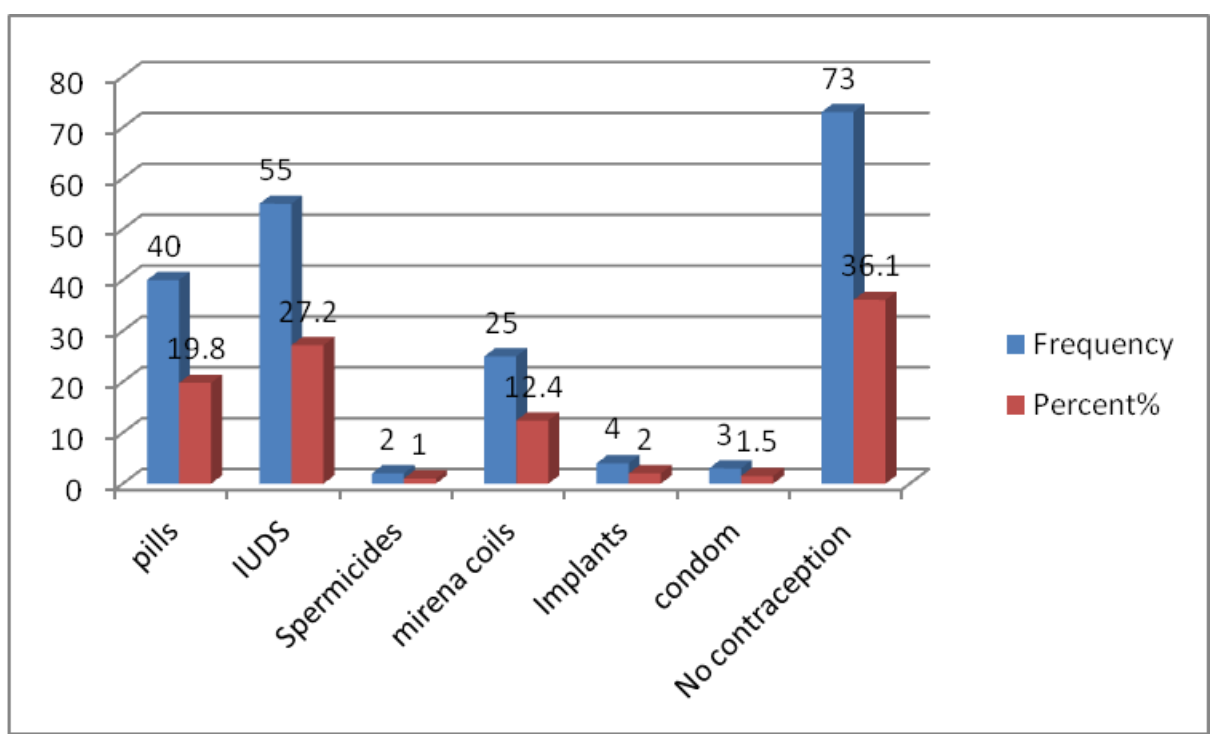

Figure4. Distribution of Patients according to contraception type (N=202) 
Common Infectious Agent in Urogenital Tract among Ladies at Omdurman Locality in Omdurman Maternity Hospital \& Elsuadi Hospital in Sudan

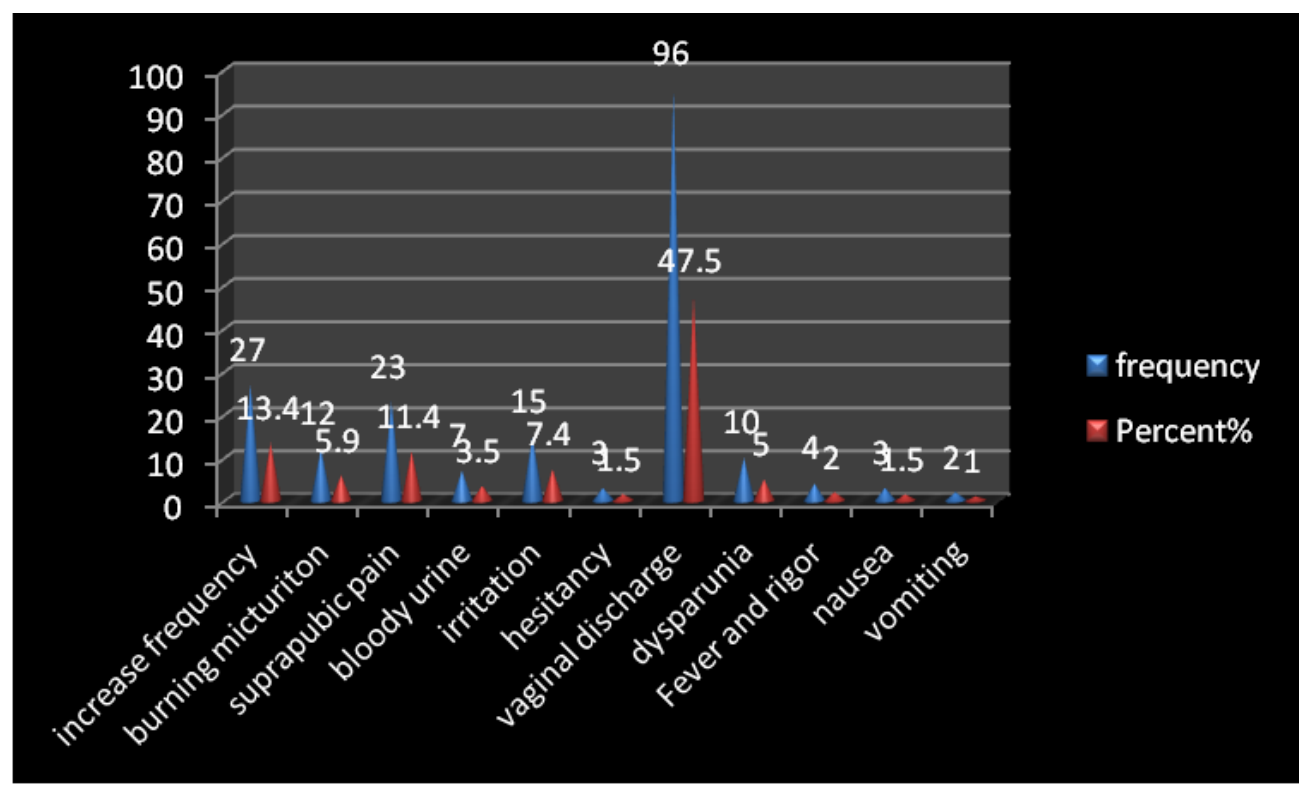

Figure5. Distribution of Patients according to type of symptoms $(N=202)$

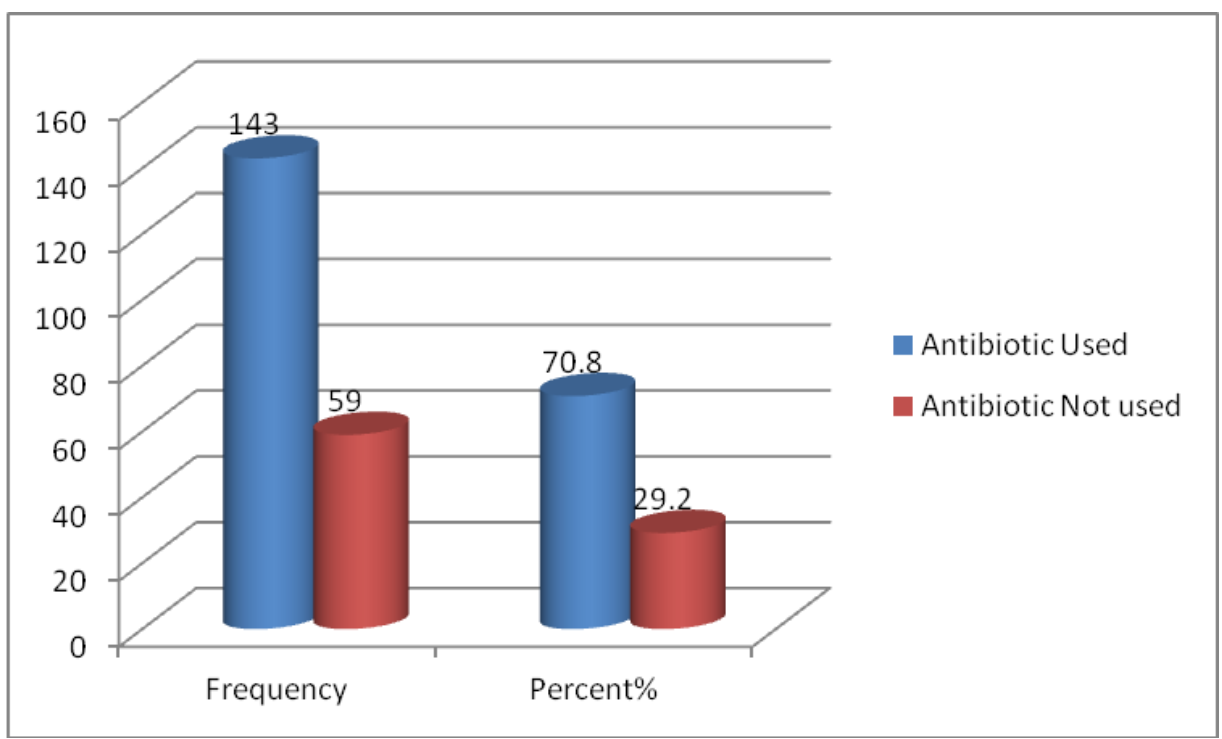

Figure6. Distribution of Patients according to antibiotic Use (N=202)

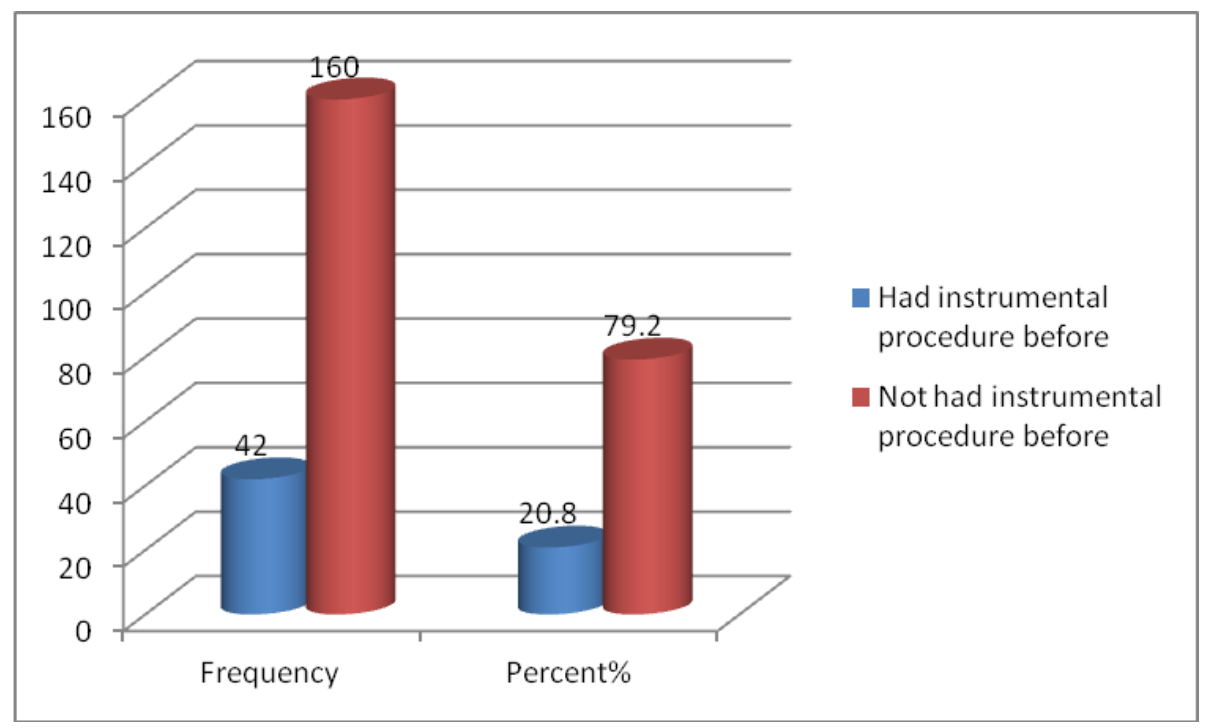

Figure7. Distribution of Patients according Instrumental Procedure $(N=202)$ 
Common Infectious Agent in Urogenital Tract among Ladies at Omdurman Locality in Omdurman Maternity Hospital \& Elsuadi Hospital in Sudan

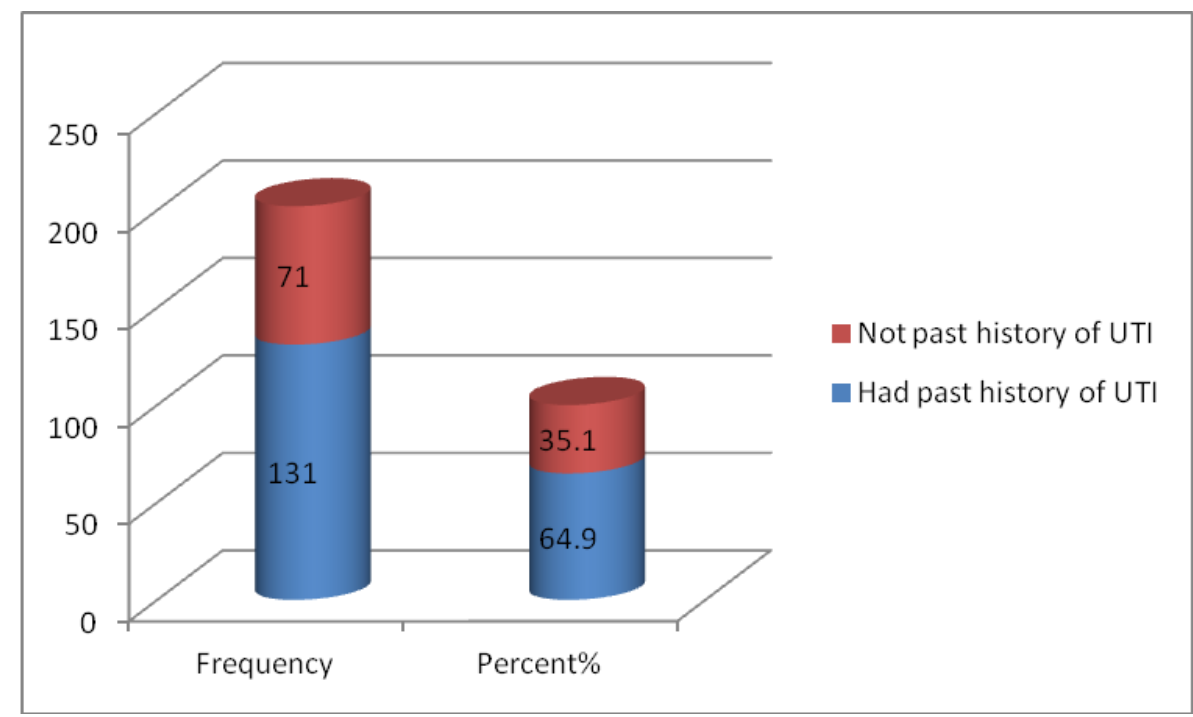

Figure8. Distribution of Patients according to History of Urogenital tract Infection (N=202)

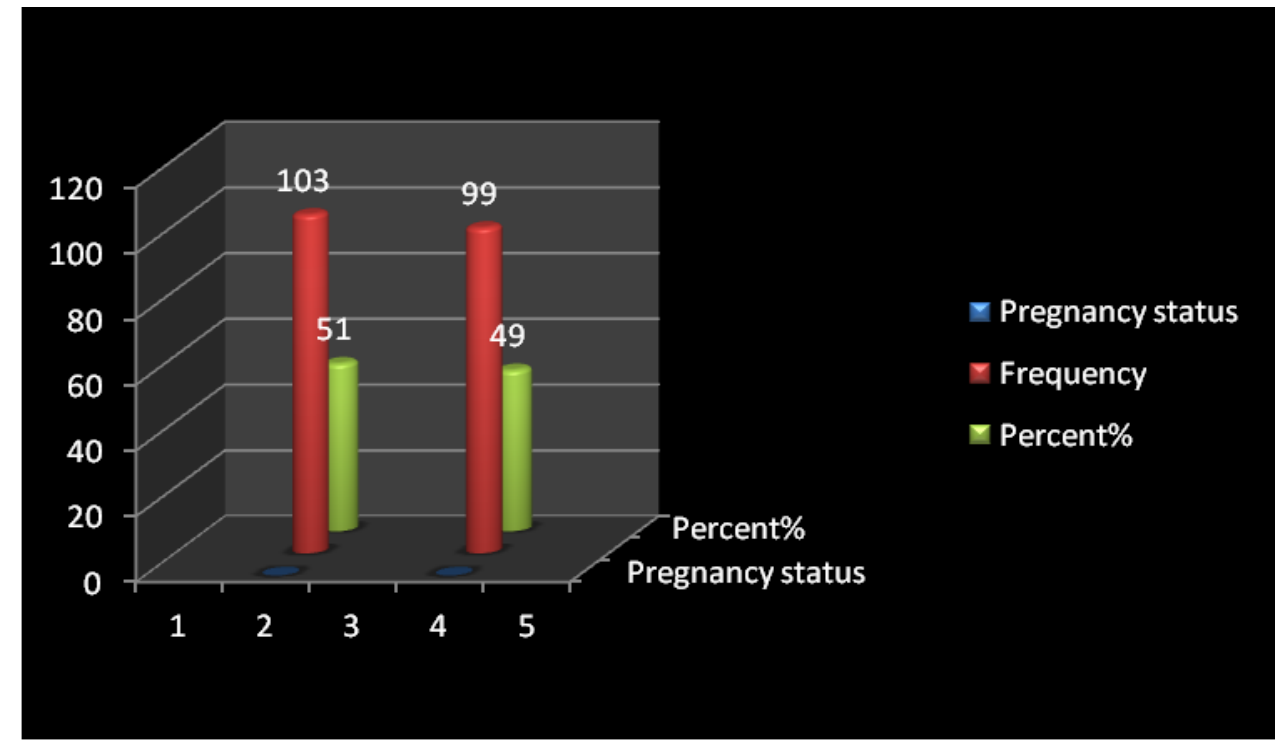

Figure9. Distribution of Patients according to Pregnancy status (N=202)

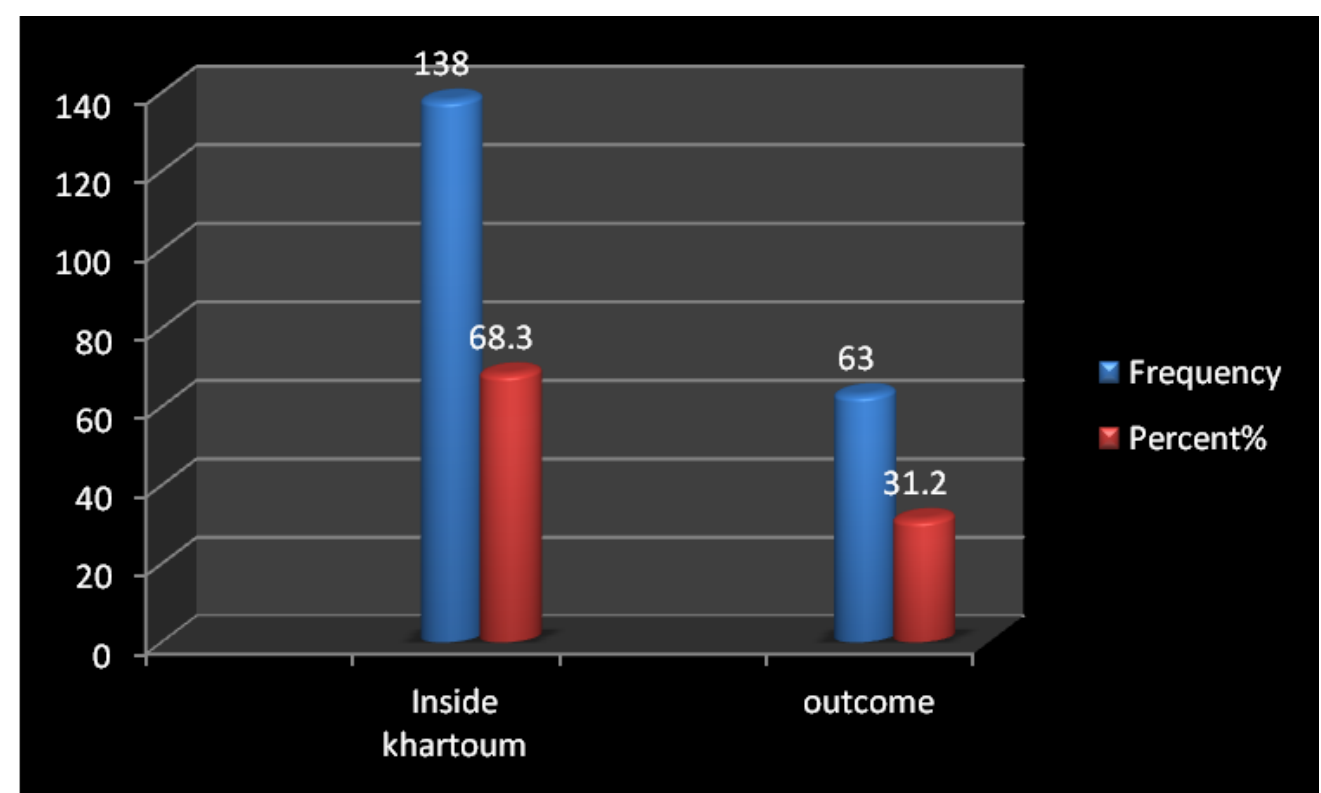

Figure10. Distribution of Patients according to Residence (N=202) 
Common Infectious Agent in Urogenital Tract among Ladies at Omdurman Locality in Omdurman Maternity Hospital \& Elsuadi Hospital in Sudan

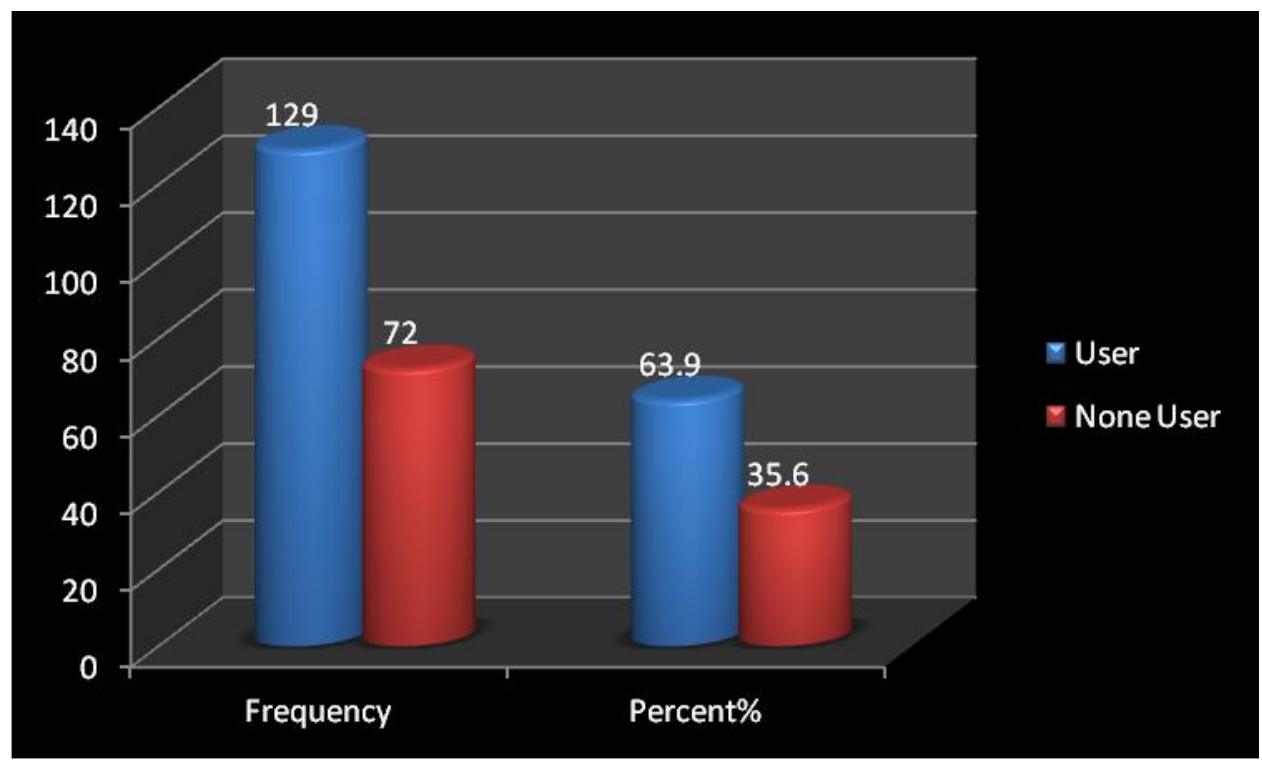

Figure11. Distribution of Patients according to Contraceptive Use (N=202)

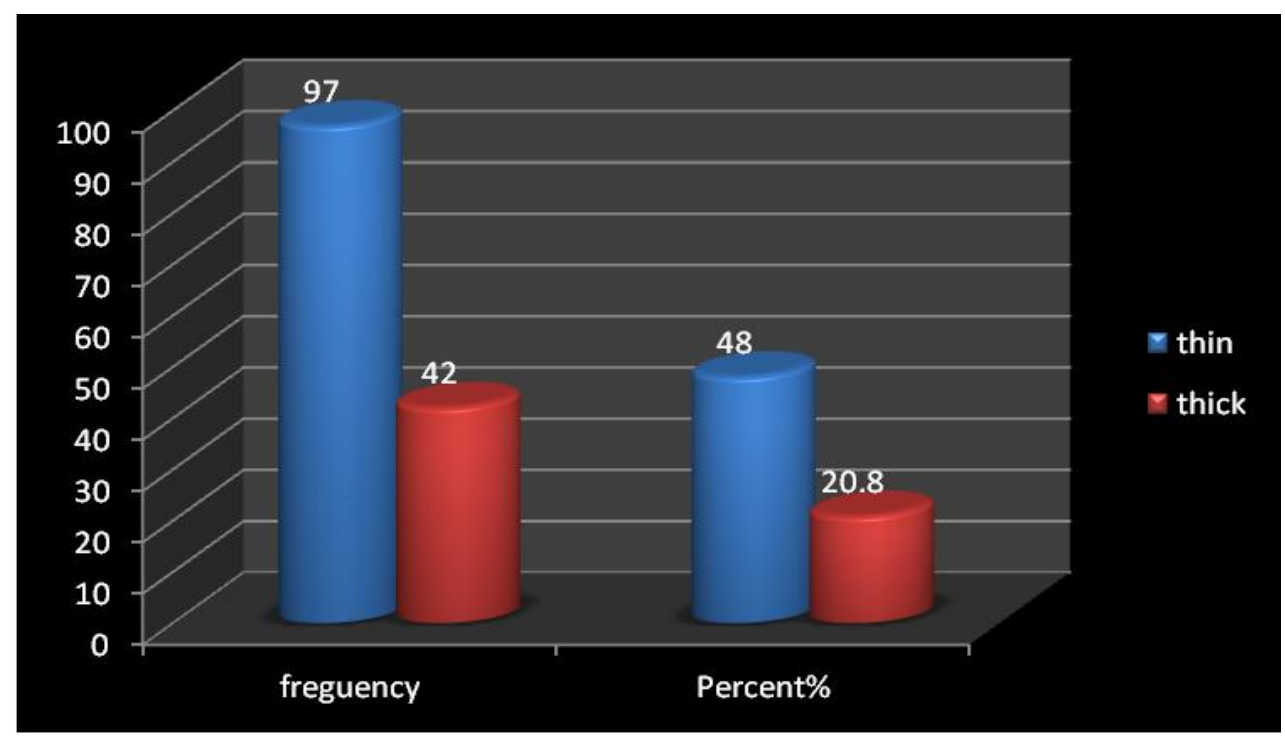

Figure12. Distribution of Patients according to Type of Discharge $(N=202)$

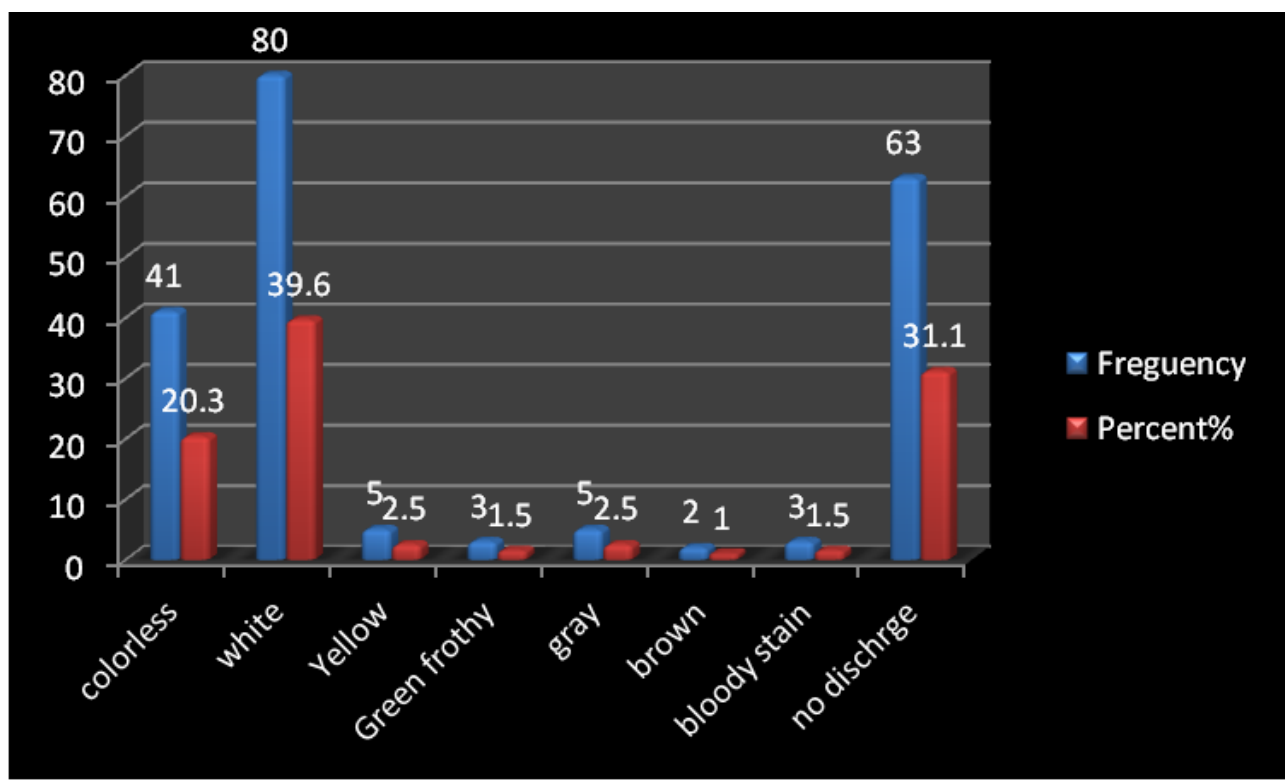

Figure13. Distribution of Patients according to color $(N=202)$ 
Common Infectious Agent in Urogenital Tract among Ladies at Omdurman Locality in Omdurman Maternity Hospital \& Elsuadi Hospital in Sudan

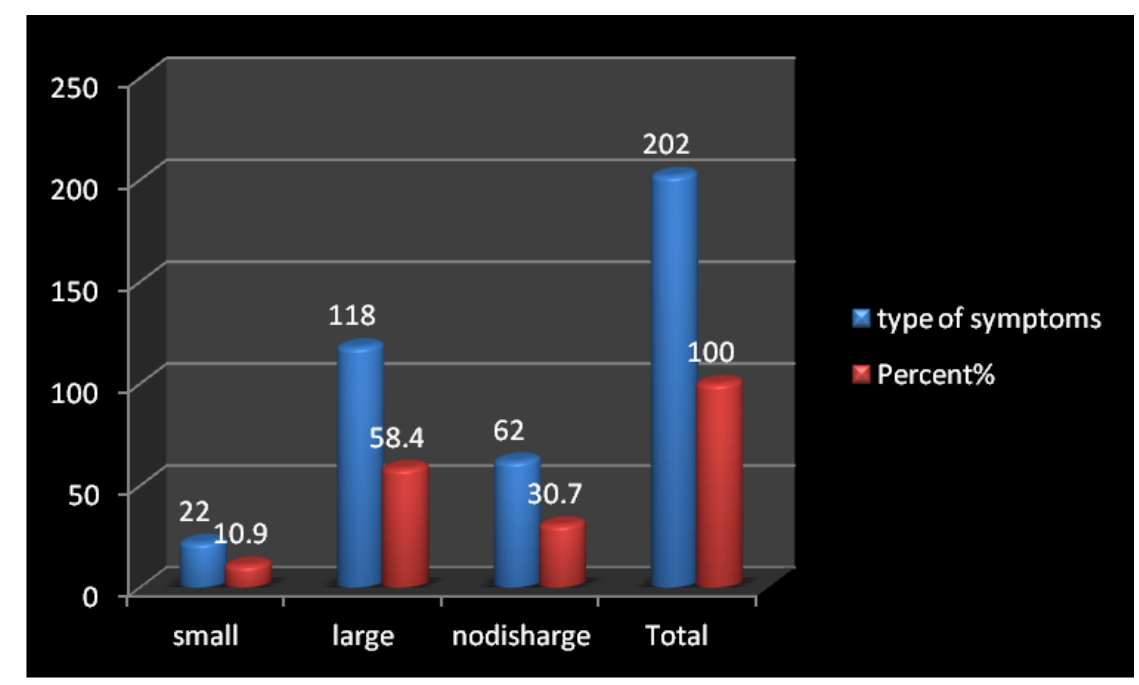

Figure14: Distribution of Patients according to Amount of Discharge $(N=202)$

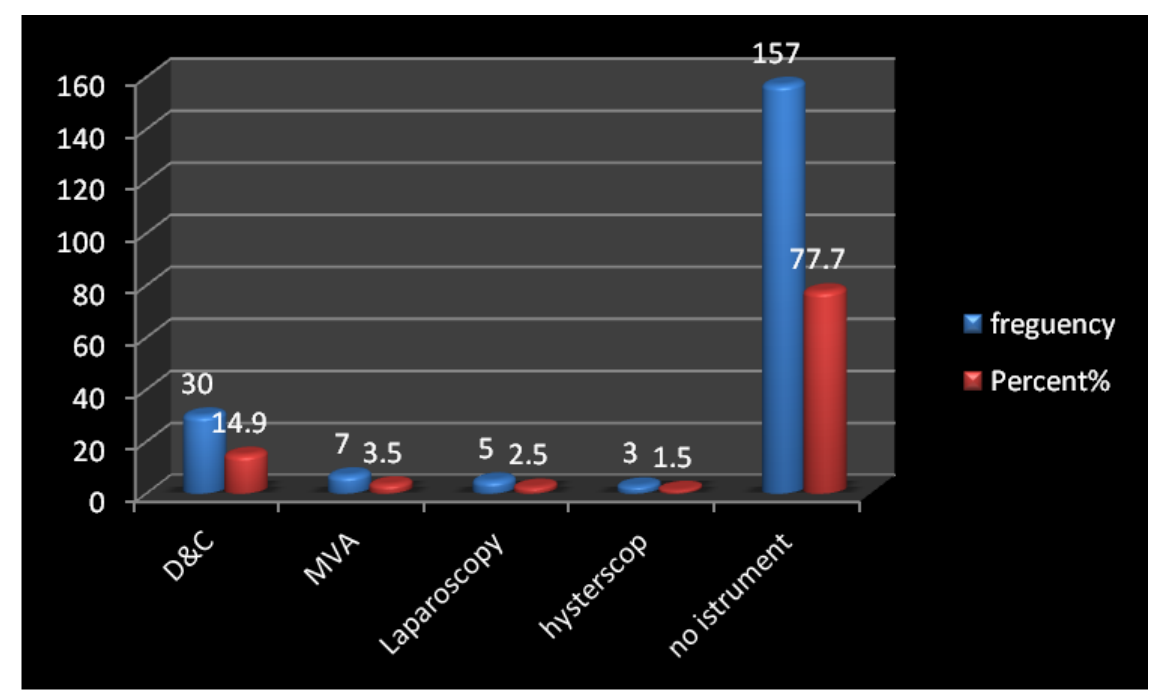

Figure15. Distribution of Patients according to Type of Instrument (N=202)

\section{DISCUSSION}

Genitourinary tract contaminations of Sudanese ladies are basic medical issues that lead to genuine restorative confusions and outcomes. This examination explores and decides causative microorganism and their antimicrobial medication affectability and obstruction of the 202 ladies remembered for the investigation, $179(88,6 \%)$ has a positive outcome in high vaginal swab for a wide range of microorganism, while $23(11.4 \%)$ has no growth and $138(68.3 \%)$ were positive in urine culture and 64 (31.6\%) were negative.

The pattern of microorganism in high vaginal Swab Candida was $27.3 \%$ it was the most frequent microorganism, Staphaaureus $16.9 \%$ is second causative microorganism, followed by proteus $9.9 \%$, Ecoli $7.9 \%$, Kellibesila 5.9\%, Trichomonas vaginalis were $4.5 \%$, Coliform $4.5 \%$, streptococcus $3.5 \%$, normal flora $3.9 \%$ and least infection by bacterial vaginosis were $4(2 \%)$.
The pattern of microorganism in urine culture. Ecoli was the most causative microorganism $21.8 \%$, Staphaaureus $14.4 \%$, streptococcus were $9.4 \%$, proteus were $8.9 \%$, Kellibesila $8.4 \%$, pseudomonas were $2 \%$, Candida were three 1.5 $\%$ Trichomonas vaginalis were two $(.9 \%)$ and Enterococcus were two ( $.9 \%)$.

Genitourinary tract contaminations of Sudanese ladies are normal medical issues that lead to genuine medicinal difficulties and results. This examination explores and decides causative microorganism and their antimicrobial medication affectability and obstruction Of the 202 ladies remembered for the investigation, $179(88,6 \%)$ of the 179 vaginal disease cases, the causative operators changed from single contamination brought about by one sort of microorganism to polymicrobial diseases, an allout number of 197. Critical microorganisms were distinguished by lab techniques. Most of ladies were tainted by one living being $80.7 \%$, 
$163 / 179$ and two life forms 6.9\%, 14/179, trailed by three life forms $1 \%, 2 / 179$.

In this examination Candida was the most widely recognized microorganism is found in $27.2 \%$, in contrast with a past report led on a comparative populace in Sudan, our investigation announced higher rates $(27.2 \%)$ of candidiasis than the $10.1 \%$ revealed by Kafi et al. [8]. Interestingly, these creators recorded $7.7 \%$ of genital contaminations because of Trichomoniasis, which was higher than the $3 \%$ in our examination. In another investigation completed in Khartoum, the occurrence of C. trachomatis, T. Vaginalis, N. gonorrhea, and candidiasis among pregnant ladies going to an antenatal center was accounted for to be $7.3 \%$ in patients enduring numerous contaminations ${ }^{[7]}$. The variety of these seclusion rates might be expected to financial status and invulnerability of patients, or natural, dietary, or social factors, the frequency of candidiasis was lower than ponders from Vietnam (25.3-34 \%), This variety could be the distinction in study members as the present examination included pregnant, non-pregnant, symptomatic ladies in regenerative age.

This was intelligible with an examination led in Vietnam ${ }^{[1]}$, Bangladesh ${ }^{[18]}$ and Nepal ${ }^{[19]}$ where candidiasis pursued by $\mathrm{BV}$ was the most common. Be that as it may, it contrasts from an investigation done in India [15] where Trichomoniasis was the most pervasive. In this examination, the most elevated extent of BV was seen among pregnant ladies than with no pregnant ladies. This was reliable with reports from Addis Ababa, Ethiopia ${ }^{[25]}$ pursued by Staphaaureus contamination $16.8 \%$, Proteus 9.9\%, Ecoli 7.9\%, and Kellibesila $5.9 \%$ with low frequencies of Chlamydia $4.5 \%$, Trichomonas vaginalis is found $3 \%$, all Trichomoniasis cases were recognized distinctly from wedded ladies. This was in accordance with an examination led in Nepal ${ }^{[19]}$. This fortifies the huge job of sex in inclining ladies to Trichomoniasis. Additionally, candidiasis was higher in hitched ladies contrasted with others. A comparative discovering was accounted for in India ${ }^{[15]}$. This may be on the grounds that wedded ladies are bound to get pregnant and pregnancy is known to be a hazard factor for candidiasis.

The frequency of Trichomoniasis was similar to examines completed in Kerkuk-Iraq (2.9 \%), Thandalam (2.1\%), Shandong (2.9\%) and USA $(2.8 \%)[14,17,20,28]$. Be that as it may, it was higher than an investigation in Sudan $(0.5 \%)$, Vietnam $(0.4 \%)$, Turkey $(1.1 \%)$ and Hanol Vietnam $(1.3 \%)[1,2,22,29]$. Interestingly, the occurrence was lower than examines did in Jimma, Ethiopia $(4.98 \%)^{[9]}$, Brazil $(4.1 \%)^{[23]}$ and India $(18.8 \%)^{[30]}$. The watched contrast could be because of variety in pregnancy status, individual cleanliness practice, condition, invulnerability, financial and social elements of the investigation members. This discovering complies with an examination finding in Shandong ${ }^{[20]}$. This is because of the way that ladies at this age are increasingly inclined to vaginitis identified with visit sexual exercises with spouses, pregnancy, debilitating of insusceptibility and oral prophylactic use. Coliform 3\%, the frequency of $\mathrm{N}$. gonorrhoeae is $2.5 \%$, in this examination was practically identical with an investigation led in kerkuk Iraq $(0.8 \%)$, Lebanon (1\%) and Shandong (0.1 $\%)^{[14,20,27]}$.

Typical verdure $2.5 \%$ this could be because of expanded coital recurrence in non-pregnant contrasted with pregnant ladies bringing about a decrease in the physiological hindrance of the vagina, which prompts an abundance of ordinary commensals.

Gathering B Streptococcus vaginal colonization $(2 \%)$ in ladies of regenerative age complies with an examination directed in South India $(2.3 \%)$ [34]. In any case, it was lower than reports from another piece of Ethiopia (20.9 \%), Argentina (7.6\%) and Japan [35-37]. This irregularity may be related with the distinction among study members.

Bacterial vaginosis frequency in this examination was $2 . \%$ in concurrence with ponders directed in Hanol Vietnam $(3.5 \%)$ and Tribhuvan $(2.5 \%)$ [22, 24]. In any case, it was lower than reports from Addis Ababa, Ethiopia $(19.4 \%)$, and pseudomonas $1.5 \%$.

Urinary tract disease in this examination found exceptionally brought about by E. coli and it was the most overwhelming pathogen with generally speaking separation paces of $21.8 \%$, lower than discoveries have been accounted for in Yemen, $41.5 \%$, Nigeria, $42.1 \%$ Khartoum North Emergency clinic, Sudan $42.4 \%^{[20]}$, and Tikur Anbessa Specific HospitalAddis Ababa, Ethiopia44 \%. E. coli is the most widely recognized microorganism in the vaginaland rectal zone ${ }^{[29]}$. Anatomical and utilitarian changes and trouble of keeping up individual cleanliness during pregnancy may expand the danger of obtaining UTI from E.coli. Gram- 
constructive staphylococci were the second prevailing pathogen with by and large seclusion pace of $14.4 \% \%$, practically identical discoveries were additionally detailed from Tikur Anbessa Specialized Hospital Addis Ababa, Ethiopia $16 \%$ ${ }^{(17)}$, and Tanzania $16.7 \%{ }^{(23)}$. This variety might be clarified by the distinctions in nature, social propensities for the network, the standard of individual cleanliness and training. Additionally, the way that this examination was directed among ladies who had lower stomach torments, which is an indication of UTI, instead of the general There was no relationship between maternal age, equality, gravidity, occupation, conjugal status and instruction with UTI in this investigation. This was in concurrence with examines in Tanzania ${ }^{(19)}$ and Sudan ${ }^{(20)}$.

Different investigations had before indicated that age, equality and past history of UTI were hazard factors. In any case, a closer examination of the distributed writing uncovered that the age and equality had no connection with UTI in pregnancy. For instance, a few investigations indicated that the rate of UTI expanded with age ${ }^{(22)}$, while others thought that it was more with a more youthful age gathering ${ }^{(23)}$. There was no distinction in the rate of urinary tract disease in pregnant ladies with the past history of urinary tract contamination and those without. This was as opposed to thinks about in Pakistan which had demonstrated that the past scene of UTI was a hazard consider urinary tract disease pregnancy. This may have been because of powerful treatment for the prior UTI scenes with no opposition strains.

Out of the 179 tainted ladies, in the present examination, $51 \%$ were pregnant ladies and they exhibit different kinds of vaginal diseases present in it is possible that at least one than one microorganism for each case and none pregnant were $49 \%$, among pregnant ladies the gestational age of 30-34 weeks is most contamination had been recognized $26.2 \%$, making this lady in danger of preterm work and rashness. Of these, the most well-known contaminated age bunches were $15-30$ years $54 \%$ which is the time of multiplication and ripeness in Sudan which they need screening. P. value $<0.01$. This discovering is like the discoveries of different investigations in different African nations, for example, the 32\% pace of genital contamination recorded among ladies in Ethiopia ${ }^{[19]}, 47.7 \%$ in Uganda ${ }^{[20]}$, and $62.6 \%$ in Tanzania ${ }^{[21]}$. Such proportions of pregnant ladies with positive culture may require therapeutic medicines and show the high frequency and varieties in the causal specialists related with vaginal contaminations. Concerning their symptomatic introduction $13.4 \%$ of ladies gave expanding recurrence, $11.4 \%$ gave suprapubic torment, $5.9 \%$ copying with micturition, bleeding pee were $3.5 \%$, disturbance was $7.4 \%$, aversion three $1.5 \%$, vaginal release alone $47.5 \%$, dyspareunia $5 \%$, fever, and meticulousness were $2 \%$, sickness $1.5 \%$ and retching $1 \%$. As to vaginal release, $56.9 \%$ of ladies gave the release with tingling and $11.9 \%$ gave a release without tingling and $31.2 \%$ no release, of the release with terrible smell were $42.1 \%$, release without awful scent were $26.7 \%$. Hazard factors for urogenital tract contaminations study found that ladies utilized contraception most connected with genitourinary disease is $27.2 \%$, anti-microbial utilized in $70.8 \%$ reflecting intermittent contamination, instrumental methodology was distinguished in $20.8 \%$ had instrumental system, $64.9 \%$ had past history of urogenital contamination likewise sexually transmitted disease were $44.6 \%$ kidney contamination $15 \%$, uncomplicated UTI $15 \%$. with history of steroids were $5.9 \%, 10.4 \%$ has history of diabetes so genital tract disease has solid relationship with intermittent contamination and anti-infection agents client that vital there screening. The vast majority of ladies $48 \%$ gave slight vaginal release, $20.8 \%$ with thick vaginal release and no release were $31.2 \%$, those giving vapid were $20 \%$ while $39.6 . \%$ were white release, yellow release was $2.5 \%$, green foamy release were $31.5 \%$ and $\operatorname{dim}$ was $2.5 \%$ while darker release was $1 \%$, wicked stain release was $1.5 \%$ and no release was $31.1 \%$. $10.9 \%$ were had a modest quantity of release while $58.4 \%$ were had a huge sum and no release was $31.2 \%$ so vaginal release in ladies legitimizes their way of life.

At the point when the nearby assessment has done examination discovered $68.3 \%$ has vaginal release, neighborhood aggravation in $11.4 \%$ and no release no irritation $20.3 \%$, so ladies analyze dependent on culture, and development result $88,6 \%$ has positive outcomes while $11.4 \%$ has no development.

As per the sort of instrumental utilized $14.9 \%$ were done $\mathrm{D} \& \mathrm{C}$ while 3.5 . \% were done MVA, $2.5 \%$ were done laparoscopy while $1.5 \%$ were done a hysteroscopy and non-instrumental utilized were $77.7 \%$. The high vaginal swap was accomplished for 202 symptomatic ladies, additionally pee for culture and affectability was accomplished for the equivalent 202 symptomatic 
Common Infectious Agent in Urogenital Tract among Ladies at Omdurman Locality in Omdurman Maternity Hospital \& Elsuadi Hospital in Sudan

\section{CONCLUSION}

The most incidence of vaginal infection in this study is candidiasis $27.3 \%$ followed by Staphaaureus $16.9 \%$, proteus $9.9 \%$ and Ecoli $7.9 \%$, Ecoli is the most incidence urinary tract infection $21.8 \%$ followed by Staphaaureus $14.4 \%$, streptococcus $9.4 \%$ and proteus $8.9 \%$ with applying international standard clinical criteria supports the diagnosis our microbial isolates showed typical biological features, however, the clinical features did not always concur.

The associated symptoms of burning micturiton, pain during voiding and increased frequency of urination can be a source of great discomfort and can greatly affect patients' Therefore screening of vaginal diseases in ladies of regenerative age ought to be actualized.

Uncomplicated UTIs are typically treated experimentally with anti-infection agents. Be that as it may, anti-toxins ought not be endorsed too much, especially in perspective on the expanding frequency of anti-microbial opposition. Therefore screening for vaginal infections in the routine check-up during pregnancy should be included and big effort is needed to clarify whether screening and treatment of vaginal infections improves maternal and neonatal outcomes.

\section{RECOMMENDATION}

- Routine vaginal swab and pee societies ought to be performed on every single pregnant lady during pre-birth visits, particularly during the second and third trimesters. Administration of broad spectrum antibiotic for simple urinary tract should be avoided as it increase antibiotic resistance.

- Genitourinary unit should be available in hospitals to early detection and treatment as infection spread widely.

- Counsllenig of women about different genitourinary tract infection and raise their awareness will reduce infection and optimize maternal and fetal out comes.

- Further research is needed to study different women groups, to improve the sensitivity of existing treatment modality.

\section{REFERENCES}

[1] Cauci S, Driussi S, De santo D, et al. incidence of bacterial vaginosis and vaginal flora changes in peri- and postmenopausal women, J clinMicrobiol 20012; 99:2147-52.

[2] Ferris DG, Nyirjesy P, sobel JD,et al. over the counter antifungal drug misuse associated with patient - diagnosis vulvovaginal candidiasis . Obset Gynae 2012; 14: 419-25.

[3] Hooton TM,schools D,hughes, JP,et, al.a prospective study of risk factors for symptomatic UTI in young women. N Engl J Med 2011; 335:468-74.

[4] Postgrad med J 2013; 79:428-432 doi:10.113 6/pmj.79.934.428.

[5] Lowe NK,ryan -wenger NA. Aclinical test of women self-diagnosis of genitourinary infection. cli Nurs Res 2000;9:144-60.

[6] Czaja CA, Hooton TM. Update on acute uncomplicated urinary tracinfection in women. Postgrad Med 2006; 119:39-45.

[7] Foxman B, Barlow R, D'Arcy H, Gillespie B, Sobel JD. Self reportedincidence of urinary tract infection and associated costs. Ann Epidemiol ,2000;10:509

[8] American College of Obstetricians and Gynecologists. Treatment of urinary tract infection in non-pregnant women. ACOG Practice Bulletin No. 91,

[9] Hooton. Recurrent urinary tract infection in women. Int J Antimicrobial Agents 2001; 17:259-268 .

[10] Car J. Urinary tract infections in women: diagnosis and management in primary care. BMJ 2006;332:94-7.

[11] Simerville JA, Maxted WC, Pahira JJ. Urinalysis: a comprehensive review. Am Fam Physician 2005; 71:1153-62.

[12] Romero R, Oyarzun E, Mazor M, Sirtori M, Hobbins JC, Bracken M. Meta-analysis of the relationship between asymptomatic bacteriuria and preterm delivery/low birth weight. Obstet Gynecol 1989;73:576-82.

[13] Pfau A, Sacks TG. Effective prophylaxis for recurrent urinary tract infection during pregnancy. Clin Infect Dis 1992; 14:810-4.

[14] Ovalle A, Levancini M. Urinary tract infections in pregnancy. Curr Opin Urol 2001:11:55-9.

Citation: Kunna A et.al, "Common Infectious Agent in Urogenital Tract among Ladies at Omdurman Locality in Omdurman Maternity Hospital \& Elsuadi Hospital in Sudan”, International Journal of Research Studies in Medical and Health Sciences. 2020; 5(6): 39-53.

Copyright: () 2020 Kunna A et.al, This is an open-access article distributed under the terms of the Creative Commons Attribution License, which permits unrestricted use, distribution, and reproduction in any medium, provided the original author and source are credited. 